\title{
Long-term and high-frequency non-destructive monitoring of water stable isotope profiles in an evaporating soil column
}

\author{
Y. Rothfuss, S. Merz, J. Vanderborght, N. Hermes, A. Weuthen, A. Pohlmeier, H. Vereecken, and N. Brüggemann \\ Forschungszentrum Jülich GmbH, Institute of Bio- and Geosciences, Agrosphere Institute (IBG-3), Leo-Brandt-Straße, \\ 52425 Jülich, Germany
}

Correspondence to: Y. Rothfuss (y.rothfuss@fz-juelich.de)

Received: 12 March 2015 - Published in Hydrol. Earth Syst. Sci. Discuss.: 14 April 2015

Revised: 8 September 2015 - Accepted: 20 September 2015 - Published: 6 October 2015

\begin{abstract}
The stable isotope compositions of soil water $\left(\delta^{2} \mathrm{H}\right.$ and $\delta^{18} \mathrm{O}$ ) carry important information about the prevailing soil hydrological conditions and for constraining ecosystem water budgets. However, they are highly dynamic, especially during and after precipitation events. In this study, we present an application of a method based on gas-permeable tubing and isotope-specific infrared laser absorption spectroscopy for in situ determination of soil water $\delta^{2} \mathrm{H}$ and $\delta^{18} \mathrm{O}$. We conducted a laboratory experiment where a sand column was initially saturated, exposed to evaporation for a period of 290 days, and finally rewatered. Soil water vapor $\delta^{2} \mathrm{H}$ and $\delta^{18} \mathrm{O}$ were measured daily at each of eight available depths. Soil liquid water $\delta^{2} \mathrm{H}$ and $\delta^{18} \mathrm{O}$ were inferred from those of the vapor considering thermodynamic equilibrium between liquid and vapor phases in the soil. The experimental setup allowed for following the evolution of soil water $\delta^{2} \mathrm{H}$ and $\delta^{18} \mathrm{O}$ profiles with a daily temporal resolution. As the soil dried, we could also show for the first time the increasing influence of the isotopically depleted ambient water vapor on the isotopically enriched liquid water close to the soil surface (i.e., atmospheric invasion). Rewatering at the end of the experiment led to instantaneous resetting of the stable isotope profiles, which could be closely followed with the new method.
\end{abstract}

From simple soil $\delta^{2} \mathrm{H}$ and $\delta^{18} \mathrm{O}$ gradients calculations, we showed that the gathered data allowed one to determinate the depth of the evaporation front (EF) and how it receded into the soil over time. It was inferred that after 290 days under the prevailing experimental conditions, the EF had moved down to an approximate depth of $-0.06 \mathrm{~m}$. Finally, data were used to calculate the slopes of the evaporation lines and test the formulation for kinetic isotope effects. A very good agreement was found between measured and simulated values (Nash and Sutcliffe efficiency, NSE $=0.92$ ) during the first half of the experiment, i.e., until the EF reached a depth of $-0.04 \mathrm{~m}$. From this point, calculated kinetic effects associated with the transport of isotopologues in the soil surface air layer above the EF provided slopes lower than observed. Finally, values of kinetic isotope effects that provided the best model-to-data fit (NSE $>0.9$ ) were obtained from inverse modeling, highlighting uncertainties associated with the determinations of isotope kinetic fractionation and soil relative humidity at the $\mathrm{EF}$.

\section{Introduction}

Stable isotopologues of water, namely, ${ }^{1} \mathrm{H}^{2} \mathrm{H}^{16} \mathrm{O}$ and ${ }^{1} \mathrm{H}_{2}^{18} \mathrm{O}$, are powerful tools used in a wide range of research disciplines at different and complementary temporal and spatial scales. They provide ways of assessing the origin of water vapor (e.g., Craig, 1961; Liu et al., 2010), solving water balances of lakes (Jasechko et al., 2013) and studying groundwater recharge (Blasch and Bryson, 2007; Peng et al., 2014). Analysis of the isotope compositions $\left(\delta^{2} \mathrm{H}\right.$ and $\left.\delta^{18} \mathrm{O}\right)$ of soil surface and leaf waters allows for partitioning evapotranspiration into evaporation and transpiration (e.g., Yepez et al., 2005; Rothfuss et al., 2012; Dubbert et al., 2013; Hu et al., 2014).

Moreover, from soil water $\delta^{2} \mathrm{H}$ and $\delta^{18} \mathrm{O}$ profiles, it is also possible to derive quantitative information, such as soil evaporation flux, locate evaporation fronts, and root water uptake depths (Rothfuss et al., 2010; Wang et al., 2010). Zimmermann et al. (1967) and later Barnes and Allison (1983, 1984) and Barnes and Walker (1989) first analytically de- 
scribed soil ${ }^{1} \mathrm{H}^{2} \mathrm{H}^{16} \mathrm{O}$ and ${ }^{1} \mathrm{H}_{2}^{18} \mathrm{O}$ movement at steady/nonsteady state and in isothermal/non-isothermal soil profiles. Between precipitation events, the soil water $\delta^{2} \mathrm{H}$ and $\delta^{18} \mathrm{O}$ profiles depend on flux boundary conditions, i.e., fractionating evaporation and non-fractionating capillary rise as well as on soil properties (e.g., soil tortuosity). In a saturated soil, the excess of heavy isotopologues at the surface due to evaporation diffuses back downwards, leading to typical and welldocumented exponential-shaped $\delta^{2} \mathrm{H}$ and $\delta^{18} \mathrm{O}$ profiles. For an unsaturated soil, assuming in a first approximation that isotope movement occurs in the vapor phase above the soil evaporation front (EF) and strictly in the liquid phase below it, the maximal soil water $\delta^{2} \mathrm{H}$ and $\delta^{18} \mathrm{O}$ values are no longer observed at the surface but at the depth of the EF. Above the EF in the so-called "vapor region", according to Fick's law, soil water $\delta^{2} \mathrm{H}$ and $\delta^{18} \mathrm{O}$ decrease towards the isotopically depleted ambient atmospheric water vapor $\delta^{2} \mathrm{H}$ and $\delta^{18} \mathrm{O}$. Braud et al. (2005), Haverd and Cuntz (2010), Rothfuss et al. (2012), Singleton et al. (2004) and Sutanto et al. (2012) implemented the description of the transport of ${ }^{1} \mathrm{H}^{2} \mathrm{H}^{16} \mathrm{O}$ and ${ }^{1} \mathrm{H}_{2}^{18} \mathrm{O}$ in physically based soil-vegetationatmosphere transfer (SVAT) models (HYDRUS 1D, SiSPATIsotope, soil-litter-iso, TOUGHREACT). In these models, movement of soil ${ }^{1} \mathrm{H}^{2} \mathrm{H}^{16} \mathrm{O}$ and ${ }^{1} \mathrm{H}_{2}^{18} \mathrm{O}$ occurs in both phases below and above the $\mathrm{EF}$, and heat and water transports are properly coupled.

However, these tools suffer from the comparison with other "traditional" methods developed to observe and derive soil water state and transport. In contrast with soil water content and tension measured by, e.g., time-domain reflectometry and tensiometry, isotope compositions of soil water are determined either by following destructive sampling, or non-destructively (i.e., with suction cups in combination with lysimeters for soil water tension higher than $-600 \mathrm{hPa}$; e.g., Litaor, 1988; Goldsmith et al., 2011) but with poor spatial and temporal resolution. This greatly limits their informative value. Only since recently, non-destructive methodologies based on gas-permeable membrane and laser spectroscopy can be found in the literature (Herbstritt et al., 2012; Rothfuss et al., 2013; Volkmann and Weiler, 2014; Gaj et al., 2015).

The central objective of this study was to demonstrate that a direct application of the method of Rothfuss et al. (2013) to a soil column would allow for monitoring soil water $\delta^{2} \mathrm{H}$ and $\delta^{18} \mathrm{O}$ profiles in the laboratory with high temporal resolution and over a long time period. We will demonstrate that the obtained isotope data can be used to locate the EF as it recedes into the soil during the experiment. Finally, the data will be also used to test the expression proposed by Gat (1971) and based on the Craig and Gordon (1965) model, for the determination of the slopes of evaporation lines.

\section{Material and methods}

\subsection{Isotopic analyses}

Isotopic analysis of liquid water and water vapor was performed using a cavity ring-down spectrometer (L1102-i, Picarro, Inc., Santa Clara, CA, USA), calibrated against the international primary water isotope standards VSMOW2 (Vienna Standard Mean Ocean Water), GISP (Greenland Ice Sheet Precipitation), and SLAP (Standard Light Antartic Precipitation) by liquid water injection into the vaporizer of the analyzer. The isotope compositions of primary and working standards were measured at $17000 \mathrm{ppmv}$ water vapor mixing ratio (number of replicates $=4$, number of injections per replicate $=8$ ). Mean values and standard deviations were calculated omitting the first three values of the first replicate to account for a potential memory effect of the laser spectrometer. The laser spectrometer's dependence on water vapor mixing ratio was also investigated according to the method of Schmidt et al. (2010). Hydrogen and oxygen isotope ratios of water are expressed in per mil $(\% \circ)$ on the international delta scale as defined by Gonfiantini (1978) and referred to as $\delta^{2} \mathrm{H}$ and $\delta^{18} \mathrm{O}$, respectively.

\subsection{Soil column and measurements}

The experiment was conducted in a $0.0057 \mathrm{~m}^{3}$ acrylic glass column $(0.11 \mathrm{~m}$ inside diameter, $0.60 \mathrm{~m}$ height; Fig. 1a). The bottom of the column consisted of a porous glass plate $\left(10 \times 10^{-6} \mathrm{~m}<\right.$ pore size diameter $<16 \times 10^{-6} \mathrm{~m}$ (4th class), Robu ${ }^{\circledR} \mathrm{GmbH}$, Hattert, Germany) connected to a two-way manual valve (VHK2-01S-06F, SMC Pneumatik $\mathrm{GmbH}$, Germany).

Three ports were available at each of eight different depths $(-0.01,-0.03,-0.05,-0.07,-0.10,-0.20,-0.40$, and $-0.60 \mathrm{~m}$ ): one inlet for the carrier gas, i.e., synthetic dry air $\left(20.5 \% \mathrm{O}_{2}\right.$ in $\mathrm{N}_{2}$, with approx. $20-30$ ppmv water vapor; Air Liquide, Germany), one sample air outlet, and one duct for a soil temperature $\left(T_{\mathrm{S}}\right)$ sensor (type $\mathrm{K}$ thermocouple, Greisinger electronic GmbH, Regenstauf, Germany; precision: $0.1^{\circ} \mathrm{C}$ ). An additional fourth port at depths -0.01 , $-0.03,-0.05,-0.10,-0.20$, and $-0.60 \mathrm{~m}$ was used for the measurement of soil volumetric water content $(\theta)$ (EC5, Decagon Devices, USA; precision: $0.02 \mathrm{~m}^{3} \mathrm{~m}^{-3}$ ).

At each depth inside the column a $0.15 \mathrm{~m}$ long piece of microporous polypropylene tubing (Accurel ${ }^{\circledR} \mathrm{PP}$ V8/2HF, Membrana GmbH, Germany; $1.55 \times 10^{-3} \mathrm{~m}$ wall thickness, $5.5 \times 10^{-3} \mathrm{~m}$ inside diameter, $8.6 \times 10^{-3} \mathrm{~m}$ outside diameter) was connected to the gas inlet and outlet port. The tubing offers the two advantages of being gas-permeable (pore size of $0.2 \times 10^{-6} \mathrm{~m}$ ) and exhibiting strong hydrophobic properties to prevent liquid water from intruding into the tubing. It allows for sampling of soil water vapor and, hence, the determination of the isotope composition of soil liquid water $\left(\delta_{\text {Sliq }}\right)$ in a non-destructive manner considering thermo- 

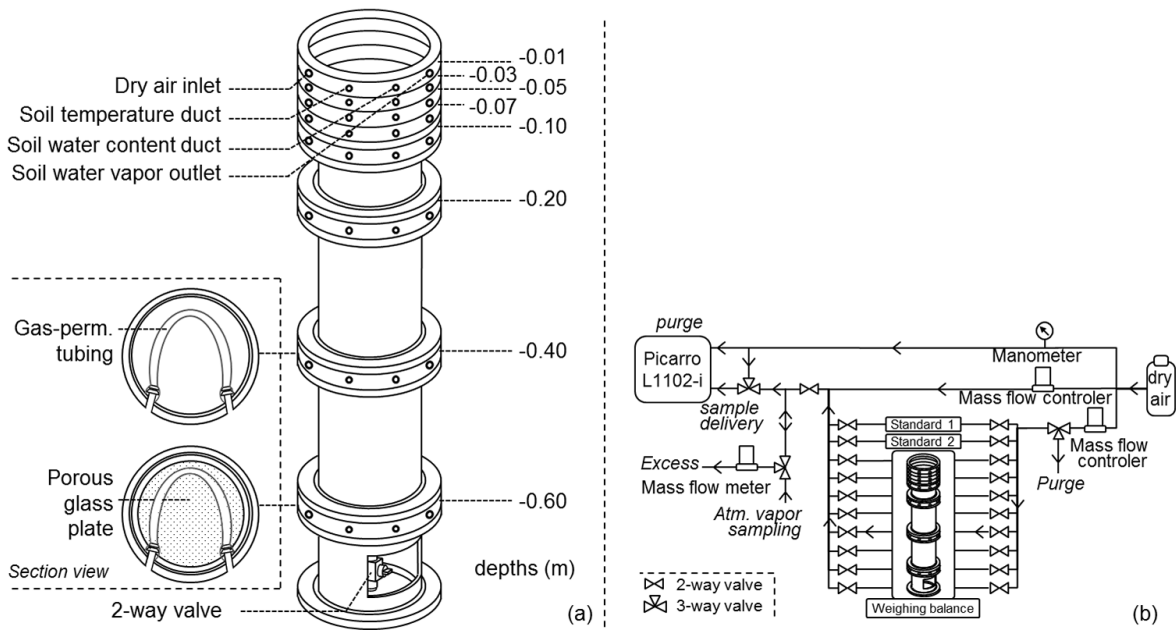

Figure 1. (a) Scheme of the acrylic glass column used in the experiment; (b) experimental setup for sampling water vapor at the different soil depths of the soil column: from the ambient air, and from the two soil water standards (standard 1 and 2).

dynamic equilibrium between liquid and vapor phases as detailed by Rothfuss et al. (2013).

\subsection{Internal isotope standards}

Two internal standards ("st1" and "st2") were prepared using the same procedure as described by Rothfuss et al. (2013). Two closed acrylic glass vessels $(0.12 \mathrm{~m}$ i.d., $0.22 \mathrm{~m}$ height), in each of which a $0.15 \mathrm{~m}$ long piece of tubing as well as a type $\mathrm{K}$ thermocouple were installed, were filled with $\mathrm{FH} 31$ sand (porosity $=0.34 \mathrm{~m}^{3} \mathrm{~m}^{-3}$, dry bulk density $=1.69 \times 10^{3} \mathrm{~kg} \mathrm{~m}^{-3}$, particle size distribution: $10 \%\left(>0.5 \times 10^{-3} \mathrm{~m}\right), 72 \%\left(0.25-0.5 \times 10^{-3} \mathrm{~m}\right)$, and $18 \%$ $\left(<0.25 \times 10^{-3} \mathrm{~m}\right)$ ) (Merz et al., 2014; Stingaciu et al., 2009). Each vessel was saturated with water of two different isotope compositions: $\delta^{2} \mathrm{H}_{\mathrm{st} 1}=-53.51( \pm 0.10) \%$, $\delta^{18} \mathrm{O}_{\mathrm{st} 1}=-8.18( \pm 0.06) \% \circ$ and $\delta^{2} \mathrm{H}_{\mathrm{st} 2}=+15.56( \pm 0.12)$ $\%$ o, $\delta^{18} \mathrm{O}_{\mathrm{st} 2}=+8.37( \pm 0.04) \%$. Soil water vapor from each vessel was sampled 8 times per day for 30 min during the whole experiment.

\subsection{Atmospheric measurements}

Laboratory air was sampled passively with a $1 / 8^{\prime \prime} 3 \mathrm{~m}$ long stainless steel tubing at $2 \mathrm{~m}$ above the sand surface for isotope analysis of water vapor $\left(\delta_{\mathrm{a}}\right)$. Air relative humidity $(\mathrm{RH})$ and temperature $\left(T_{\mathrm{a}}\right)$ were monitored at the same height with a combined RH and $T_{\mathrm{a}}$ sensor (RFT2, UMS GmbH, Germany; precision for $\mathrm{RH}$ and $T_{\mathrm{a}}$ were $2 \%$ and $0.1{ }^{\circ} \mathrm{C}$, respectively). Vapor pressure deficit (vpd) was calculated from $\mathrm{RH}$ and $T_{\mathrm{a}}$ data using the MagnusTetens formula (Murray, 1967) for saturated vapor pressure. The laboratory was air conditioned and ventilated with seven axial fans (ETRI 148VK0281, $117 \mathrm{~L} \mathrm{~s}^{-1}$ airflow,
ETRI/Rosenberg, USA) positioned at $1.80 \mathrm{~m}$ height above the sand surface.

\subsection{Sampling protocol and applied isotopic calibrations}

The column was filled in a single step with FH31 sand and carefully shaken in order to reach a dry bulk density close to in situ field conditions. The sand was then slowly saturated from the bottom from an external water tank filled with st 1 water on 2 December 2013. After saturation, the column was disconnected and sealed at the bottom using the two-way manual valve. It was finally installed on a balance (Miras 2 60EDL, Sartorius, USA), and let to evaporate for a period of 290 days in a ventilated laboratory.

$\delta_{\text {Sliq }}$ was determined in a sequential manner at each available depth once a day following the method developed by Rothfuss et al. (2013) (Fig. 1b). Dry synthetic air at a rate of $50 \mathrm{~mL} \mathrm{~min}^{-1}$ from a mass flow controller (EL-FLOW Ana$\log$, Bronkhorst High Tech, Ruurlo, the Netherlands) was directed to the permeable tubing for $30 \mathrm{~min}$ at each depth. The sampled soil water vapor was diluted with dry synthetic air provided by a second mass flow controller of the same type. This allowed for the following: (i) reaching a water vapor mixing ratio ranging between 17000 and $23000 \mathrm{ppmv}$ (where L1102-i isotope measurements are most precise) and (ii) generating an excess flow downstream of the laser analyzer. By doing this, any contamination of sample air with ambient air would be avoided. The excess flow was measured with a digital flow meter (ADM3000, Agilent Technologies, Santa Clara, CA, USA). The last 100 observations (corresponding to approx. $10 \mathrm{~min}$ ) at steady state (standard deviations $<0.70 \%$ and $<0.20 \%$ for $\delta^{2} \mathrm{H}$ and $\delta^{18} \mathrm{O}$, respectively) were used to calculate the raw isotope compositions of soil water vapor $\left(\delta_{\text {Svap }}\right)$. The latter was corrected for the water vapor mixing ratio dependence of the laser analyzer 
readings with 17000 ppmv as reference level. Measurements that did not fulfill the abovementioned conditions for $\delta^{2} \mathrm{H}$ and $\delta^{18} \mathrm{O}$ standard deviations were not taken into account. Finally, these corrected values were used to infer the corresponding $\delta_{\text {Sliq }}$ at the measured $T_{\mathrm{S}}$ (Eqs. 1 and 2; taken from Rothfuss et al., 2013):

$\delta^{2} \mathrm{H}_{\text {Sliq }}=104.96-1.0342 \cdot T_{\mathrm{S}}+1.0724 \cdot \delta^{2} \mathrm{H}_{\mathrm{Svap}}$,

$\delta^{18} \mathrm{O}_{\text {Sliq }}=11.45-0.0795 \cdot T_{\mathrm{S}}+1.0012 \cdot \delta^{18} \mathrm{O}_{\text {Svap }}$.

The isotope composition of laboratory water vapor $\left(\delta_{\mathrm{a}}\right)$ was measured 8 times a day. $\delta_{\mathrm{a}}, \delta_{\text {Svap }}$ and $\delta_{\text {Sliq }}$ values were finally corrected for laser instrument drift with time, using the isotope compositions of the two water standards, $\delta_{\mathrm{st} 1}$ and $\delta_{\mathrm{st} 2}$.

Water vapor of the ambient air, of both standards, and from the different tubing sections in the soil column were sampled sequentially in the following order: soil $(0.60 \mathrm{~m})$ - soil $(0.40 \mathrm{~m})$ - atmosphere - st1 - st 2 - soil $(0.20 \mathrm{~m})$ - soil $(0.10 \mathrm{~m})$ - atmosphere - st 1 - st 2 - soil $(0.07 \mathrm{~m})$ soil $(0.05 \mathrm{~m})$ - atmosphere - st 1 - st 2 - soil $(0.03 \mathrm{~m})$ - soil $(0.01 \mathrm{~m})$. Atmosphere water vapor was sampled twice as long (i.e., $1 \mathrm{~h}$ ) as soil water vapor from the column/standards, so that each sequence lasted exactly $10 \mathrm{~h}$ and started each day at the same time. The remaining $14 \mathrm{~h}$ were used for additional standard and atmosphere water vapor measurements (i.e., on five occasions each).

\subsection{Irrigation event}

On day of experiment (DoE) 290 at 09:30 LT the sand surface was irrigated with $70 \mathrm{~mm}$ of st1 water. This was achieved over $1 \mathrm{~h}$ in order to avoid oversaturation of the sand and avoid preferential pathways that would have affected the evaporation rate. For this, a $2 \mathrm{~L}$ polyethylene bottle was used. Its bottom was perforated with a set of 17 holes of $5 \mathrm{~mm}$ diameter and its cap with a single hole through which a PTFE bulkhead union tube fitting (Swagelok, USA) was installed. The bulkhead fitting was connected to a two-way needle valve (Swagelok, USA). Opening/closing the valve controlled the flow rate at which air entered the bottle headspace, which in turn controlled the irrigation flow rate.

To better observe the dynamics directly following the irrigation event, water vapor was sampled at a higher rate, i.e., $1,3,4,5,6,9,11$, and 11 times per day at -0.60 , $-0.40,-0.20,-0.10,-0.07,-0.05,-0.03$, and $-0.01 \mathrm{~m}$, respectively. Water vapor from both standards was sampled twice a day. The experiment was terminated after 299 days on 26 September 2014.

\subsection{Evaporation lines}

Gat (1971) proposed an expression based on the model of Craig and Gordon (1965) for the slope of the so-called "evaporation line" $\left(S_{\mathrm{Ev}},[-]\right)$ which quantifies the relative change in $\delta^{2} \mathrm{H}_{\text {Sliq }}$ and $\delta^{18} \mathrm{O}_{\text {Sliq }}$ in a water body undergoing evaporation:
$S_{\mathrm{Ev}}=\frac{\Delta\left(\delta^{2} \mathrm{H}_{\text {Sliq }}\right)}{\Delta\left(\delta^{18} \mathrm{O}_{\text {Sliq }}\right)}=\frac{\left[\mathrm{RH} \cdot\left(\delta_{\mathrm{a}}-\delta_{\text {Sliq_ini }}\right)+\varepsilon_{\mathrm{eq}}+\Delta \varepsilon\right]_{{ }_{\mathrm{H}}}}{\left[\mathrm{RH} \cdot\left(\delta_{\mathrm{a}}-\delta_{\text {Sliq_ini }}\right)+\varepsilon_{\mathrm{eq}}+\Delta \varepsilon\right]_{18} \mathrm{O}}$,

where $\delta_{\text {Sliq_ini }}$ is the initial soil water (hydrogen or oxygen) liquid isotope composition, i.e., prior to removal of water vapor by fractionating evaporation. $\varepsilon_{\text {eq }}[-$, expressed in \%o] is the equilibrium enrichment in either ${ }^{1} \mathrm{H}^{2} \mathrm{H}^{16} \mathrm{O}$ or ${ }^{1} \mathrm{H}_{2}^{18} \mathrm{O}$. It is defined by the deviation from unity of the ratio between water and isotopologue saturated vapor pressures and can be calculated using the empirical closed-form equations proposed by, e.g., Majoube (1971). $\Delta \varepsilon$ [-, expressed in $\%$ ] is the so-called "kinetic isotope effect" associated with ${ }^{1} \mathrm{H}^{2} \mathrm{H}^{16} \mathrm{O}$ and ${ }^{1} \mathrm{H}_{2}^{18} \mathrm{O}$ vapor transports. Assuming that (i) turbulent transport is a non-fractionating process and considering that (ii) the ratio of molecular diffusion resistance to total resistance equals one, it follows that (Gat, 2000)

$\Delta \varepsilon=(1-\mathrm{RH}) \cdot\left(\frac{D^{v}}{D_{i}^{v}}-1\right) \cdot n$.

In Eq. (4), the product $\left(\frac{D^{v}}{D_{i}^{v}}-1\right) \cdot n$ is the kinetic isotope enrichment $\left(\varepsilon_{\mathrm{K}}[-\right.$, expressed in \%o]). In the present study, values for ratios of diffusivities $\left(D^{v} / D_{i}^{v}\right)$ were taken from Merlivat (1978):

$\left\{\begin{array}{l}\frac{D^{v}}{D_{2 \mathrm{H}}^{v}}=0.9755 \\ \frac{D^{v}}{D_{18_{\mathrm{O}}}^{v}}=0.9723\end{array}\right.$.

The term $n$ accounts for the aerodynamics in the air boundary layer and ranges from $n_{\mathrm{a}}=0.5$ (turbulent diffusion, i.e., atmosphere-controlled conditions) to $n_{\mathrm{S}}=1$ (molecular diffusion, i.e., soil-controlled conditions) with a value of twothirds corresponding to laminar flow conditions (Dongmann et al., 1974; Brutsaert, 1975). We tested the formulation proposed by Mathieu and Bariac (1996) where $n$ is considered as a function of soil water content:

$n=\frac{\left(\theta_{\text {surf }}-\theta_{\text {res }}\right) \cdot n_{\mathrm{a}}+\left(\theta_{\text {sat }}-\theta_{\text {res }}\right) \cdot n_{\mathrm{S}}}{\theta_{\text {sat }}-\theta_{\text {res }}}$,

where $\theta_{\text {res }}, \theta_{\text {sat }}$ and $\theta_{\text {surf }}$ are the residual, saturated and surface soil water contents $\left[\mathrm{m}^{3} \mathrm{~m}^{-3}\right]$, respectively.

Note that Eq. (3) contrasts with the expression for the slope characterizing equilibrium processes (e.g., precipitation formation) and therefore is strictly temperature dependent (i.e., $S_{\mathrm{eq}}=\varepsilon_{\mathrm{eq}}^{2 \mathrm{H}} / \varepsilon_{\mathrm{eq}}^{18} \mathrm{O}$ ). While $S_{\text {eq }}$ might range for instance from 7.99 to 8.94 (for temperatures between 5 and $30^{\circ} \mathrm{C}$ ), a much wider spread in $S_{\mathrm{Ev}}$ values is possible and has been measured between 2 and 6 (Barnes and Allison, 1988; Brunel et al., 1995; DePaolo et al., 2004).

\section{Results}

\subsection{Example of a measuring sequence}

Figure 2 shows exemplarily the measuring sequence for DoE 150. Soil and standard water vapor mixing ratios were 


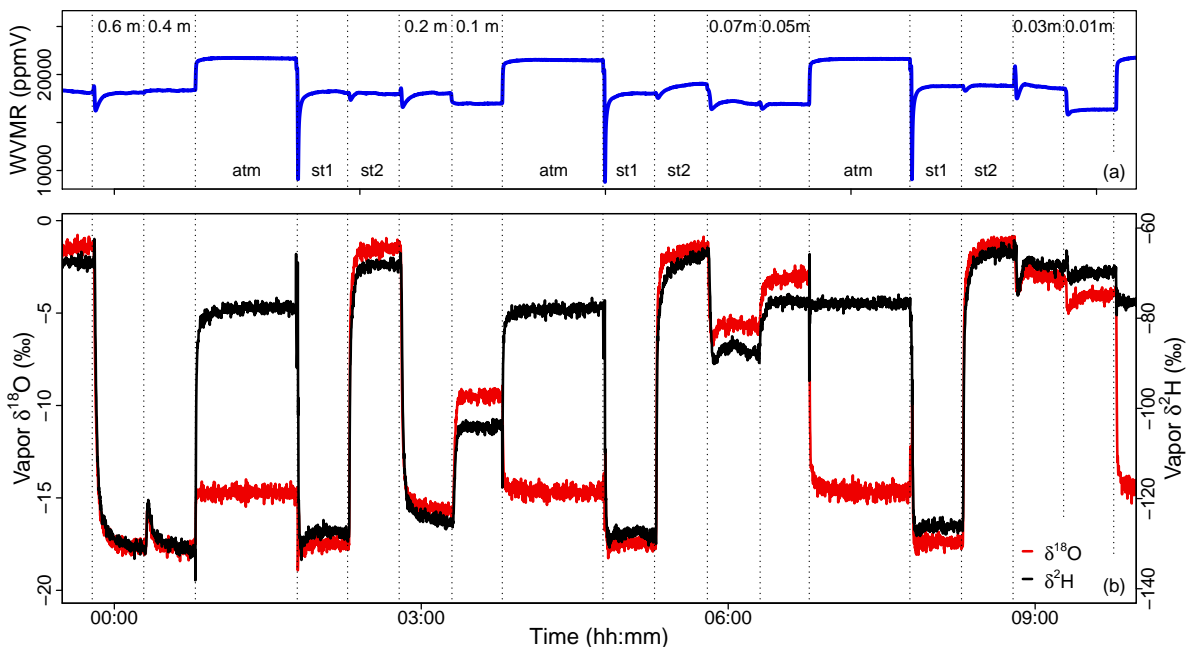

Figure 2. Water vapor mixing ratio (WVMR) and isotope composition $\left(\delta^{18} \mathrm{O}\right.$ and $\delta^{2} \mathrm{H}$; [\% VSMOW]) of the water vapor sampled on day of experiment 150 from the ambient air ("atm"), both standards ("st1" and "st2"), and from the tubing sections at soil depths 1, 3, 5, 7, 10, 20, 40 , and $60 \mathrm{~cm}$.
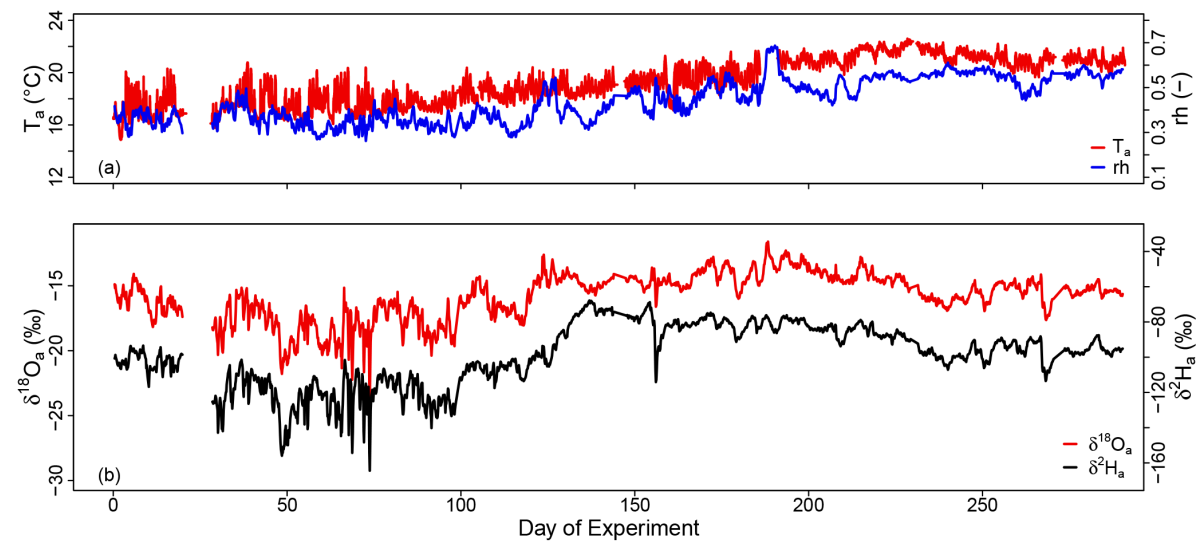

Figure 3. Time series of the laboratory ambient air temperature $\left(T_{\mathrm{a}}\right)$, relative humidity $(\mathrm{RH})$, and water vapor isotope compositions $\left(\delta^{18} \mathrm{O}_{\mathrm{a}}\right.$ and $\delta^{2} \mathrm{H}_{\mathrm{a}}$ [\%o VSMOW]) over the course of the experiment.

stable and ranged from 17200 to $18200 \mathrm{ppmv}$ during the last $10 \mathrm{~min}$ of each sampling period (Fig. $2 \mathrm{a}$ ). $\delta_{\text {Svap }}$ was within the range spanned by $\delta_{\text {st1 vap }}$ and $\delta_{\text {st2vap }}$ for both ${ }^{2} \mathrm{H}$ and ${ }^{18} \mathrm{O}$ (Fig. 2b). On DoE 150, the soil surface was sufficiently dry so that atmospheric invasion of water vapor had started to significantly influence the $\delta_{\text {Svap }}$ of the upper soil layers. Therefore, $\delta_{\text {Svap }}$ measured at $-0.01 \mathrm{~m}$ was lower than at $-0.03 \mathrm{~m}$ for both ${ }^{2} \mathrm{H}$ and ${ }^{18} \mathrm{O}$, but less pronounced for ${ }^{2} \mathrm{H}$.

\subsection{Time courses of air temperature, relative humidity and atmospheric $\delta^{2} \mathrm{H}$ and $\delta^{18} \mathrm{O}$}

During the experiment, the laboratory air temperature ranged from 15.6 to $22.5^{\circ} \mathrm{C}$ (average: $18.7 \pm 1.5^{\circ} \mathrm{C}$, Fig. 3a) and the relative humidity from 19 to $69 \%$ (average: $40 \% \pm 0.08 \%$, Fig. 3a). Lower values of $\delta_{\mathrm{a}}$ were observed from $\mathrm{DoE} 0$ to 125 at lower air temperatures, whereas higher values occurred after DoE 125 at higher air temperatures (Fig. 3b).

\subsection{Evolution of soil water content, temperature, evaporation flux and $\delta_{\text {Svap }}$ from DoE 0-290}

The soil temperature ranged from 16.2 to $22.3{ }^{\circ} \mathrm{C}$ (average: $18.6 \pm 1.3^{\circ} \mathrm{C}$, data not shown) and closely followed that in the air, i.e., differences between daily mean soil and air temperatures ranged from -0.2 to $0.2^{\circ} \mathrm{C}$ during the experiment. Following the saturation of the column, a strong decrease in water content was observed in the upper $10 \mathrm{~cm}$, whereas after 287 days the sand was still saturated at $-0.60 \mathrm{~m}$ (Fig. $4 \mathrm{a}$ ). Figure $4 \mathrm{~b}$ shows the time series of evaporation flux normalized by the vapor pressure deficit in the laboratory air (Ev/vpd, expressed in $\mathrm{mm} \mathrm{day}^{-1} \mathrm{kPa}^{-1}$ ). $\mathrm{Ev} / \mathrm{vpd}$ ratio was high at the beginning of the experiment, 

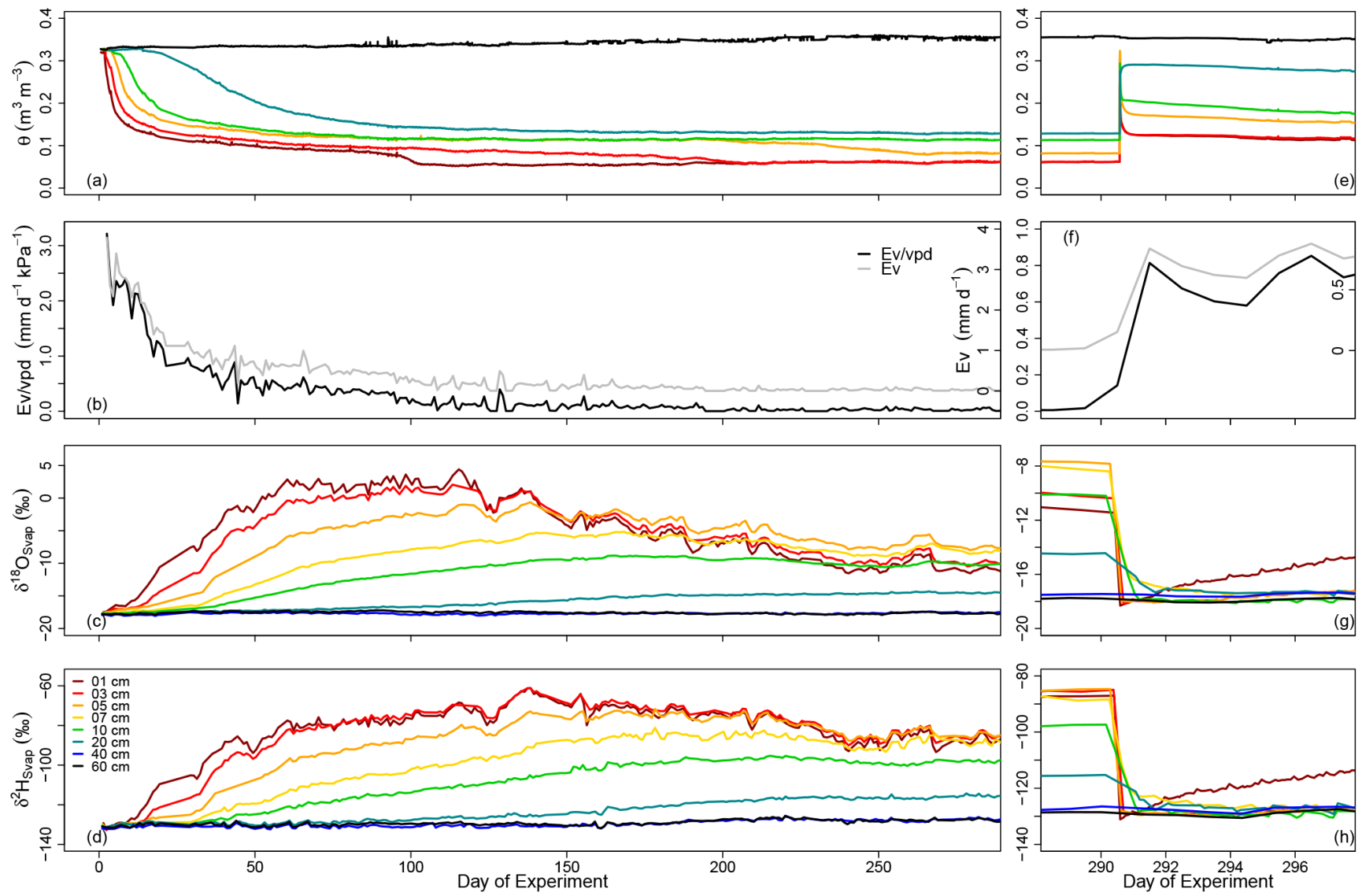

Figure 4. Time series of water content $(\theta)$, evaporation flux (Ev), evaporation flux normalized to vapor pressure deficit (Ev/vpd), and water vapor isotope compositions $\left(\delta^{18} \mathrm{O}_{\text {Svap }}\right.$ and $\delta^{2} \mathrm{H}_{\text {Svap }}$ [\%o VSMOW]) during the course of the experiment.

i.e., ranged from 2.44 to $3.22 \mathrm{~mm} \mathrm{day}^{-1} \mathrm{kPa}^{-1}$ during the first two experimental days. After DoE 180 and until the soil was irrigated, Ev/vpd stabilized around a mean value of $0.03( \pm 0.02) \mathrm{mm} \mathrm{day}^{-1} \mathrm{kPa}^{-1}$.

Due to fractionating evaporation flux, the $\delta_{\text {Svap }}$ of the topmost layer $(-0.01 \mathrm{~m})$ increased instantaneously (i.e., from DoE 0 onward) from the equilibrium $\delta_{\text {Svap }}$ value with the input water $\left(-17.3\right.$ and $-132.3 \%$ for ${ }^{18} \mathrm{O}$ and ${ }^{2} \mathrm{H}$, respectively, at $16.5^{\circ} \mathrm{C}$, Fig. $4 \mathrm{c}$ and d). Through back diffusion of the excess heavy stable isotopologues from the evaporation front, $\delta_{\text {Svap }}$ measured at depths -0.03 , $-0.05,-0.07,-0.10$, and $-0.20 \mathrm{~m}$ departed from that same equilibrium value after $2,3,10,25$, and 92 days of experiment, respectively. On the other hand, $\delta_{\text {Svap }}$ of the layers -0.40 and $-0.60 \mathrm{~m}$ were constant over the entire duration of the experiment. Until $\mathrm{DoE} 65$, the $\delta_{\text {Svap }}$ of the first $10 \mathrm{~cm}$ increased. From DoE 65 to $113, \delta_{\text {Svap }}$ reached an overall stable value in the top layers $-0.01 \mathrm{~m}$ $\left(\delta^{2} \mathrm{H}_{\text {Svap }}=4.82 \pm 2.06 \%\right.$; $\left.\quad \delta^{18} \mathrm{O}_{\text {Svap }}=11.72 \pm 67 \% o\right)$ and $-0.03 \mathrm{~m} \quad\left(\delta^{2} \mathrm{H}_{\text {Svap }}=5.61 \pm 3.14 \% ; \quad \delta^{18} \mathrm{O}_{\text {Svap }}=10.41 \pm\right.$ $0.81 \%$ ) , whereas $\delta_{\text {Svap }}$ measured at depths $-0.05,-0.07$, and $-0.10 \mathrm{~m}$ still progressively increased; from DoE 72 onward, $\delta_{\text {Svap }}$ at $-0.20 \mathrm{~m}$ started to increase. $\delta^{2} \mathrm{H}_{\text {Svap }}$ and $\delta^{18} \mathrm{O}_{\text {Svap }}$ values started to decrease after about DoE 113 and DoE 155 , respectively. $\delta^{2} \mathrm{H}_{\text {Svap }}$ at $-0.01,-0.03$, and $-0.07 \mathrm{~m}$ on the one hand and $\delta^{18} \mathrm{O}_{\text {Svap }}$ at $-0.01,-0.03$, and $-0.07 \mathrm{~m}$ on the other followed similar trends with maximum values measured below the surface down to $-0.05 \mathrm{~m}$.

\subsection{Evolution of soil water content, temperature, evaporation flux and $\delta_{\text {Svap }}$ from DoE 290 to 299}

The layers $-0.01,-0.03,-0.05,-0.10$, and $-0.20 \mathrm{~m}$ showed increases in $\theta$ of $0.31,0.22,0.30,0.23$, and $0.16 \mathrm{~m}^{3} \mathrm{~m}^{-3}$ following irrigation, whereas $\theta$ at $-0.60 \mathrm{~m}$ remained constant (Fig. $4 \mathrm{e}$ ). $\theta_{-0.01 \mathrm{~m}}$ and $\theta_{-0.03 \mathrm{~m}}$ rapidly decreased down to values of 0.12 and $0.13 \mathrm{~m}^{3} \mathrm{~m}^{-3}$. Note that when $\theta_{-0.01 \mathrm{~m}}$ and $\theta_{-0.03 \mathrm{~m}}$ reached these values prior to irrigation, the evaporation rate was similar (i.e., Ev / vpd $=0.65( \pm 0.12) \mathrm{mm} \mathrm{day}^{-1}$; Fig. $\left.4 f\right)$.

Immediately after irrigation and for both isotopologues, $\delta_{\text {Svap }}$ at $-0.01,-0.03$, and $-0.05 \mathrm{~m}$ was reset to a value close to that in equilibrium with st1 water (i.e., -17.8 and $-132.0 \%$ o for ${ }^{18} \mathrm{O}$ and ${ }^{2} \mathrm{H}$, respectively, at $21.8^{\circ} \mathrm{C}$ soil temperature; Fig. $4 \mathrm{~g}$ and $\mathrm{h}$ ). At $-0.07 \mathrm{~m}, \delta_{\text {Svap }}$ reached the 

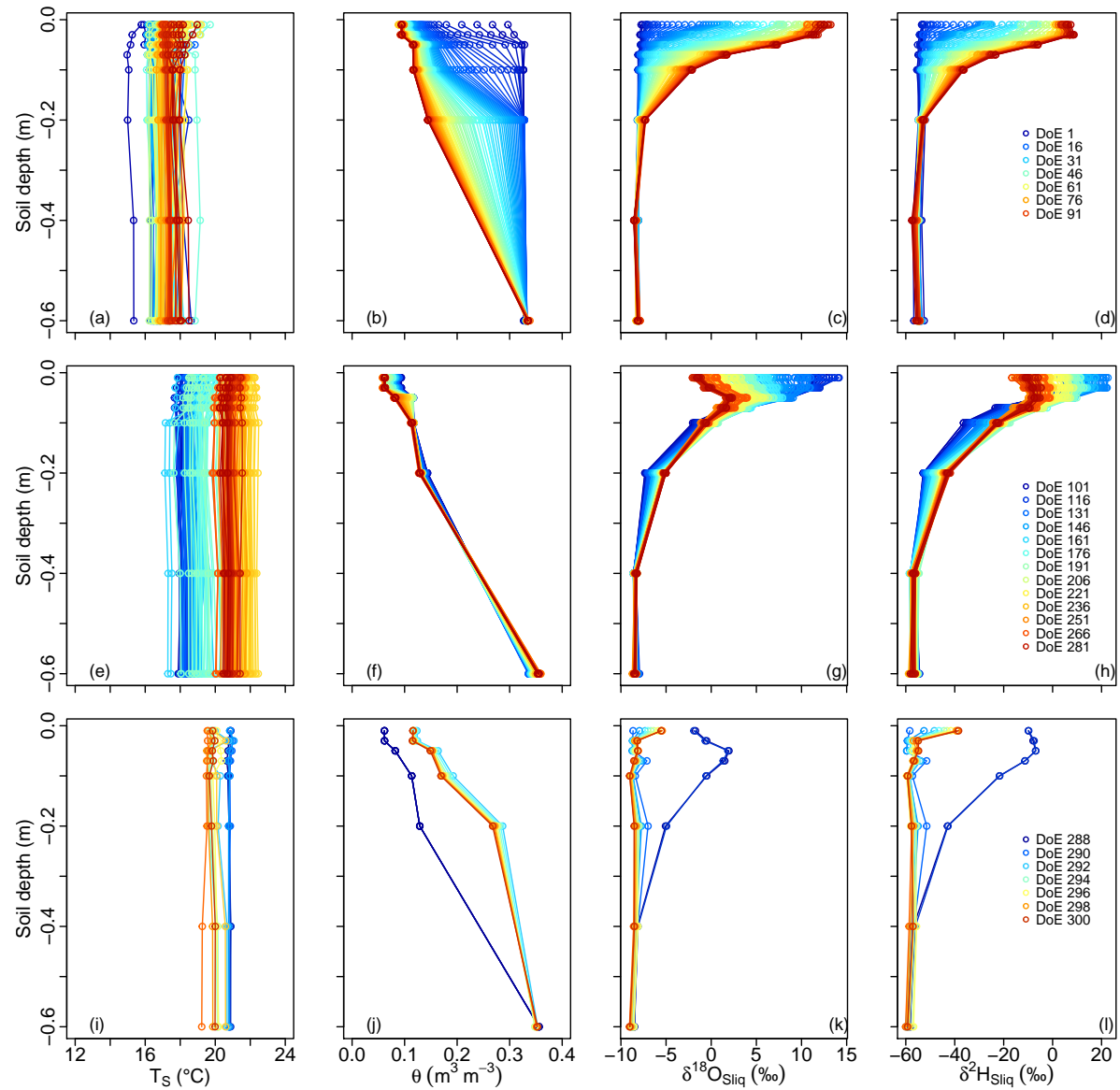

Figure 5. Soil temperature $\left(T_{\mathrm{S}}\right)$, water content $(\theta)$, and liquid water isotope compositions $\left(\delta^{18} \mathrm{O}_{\text {Sliq }}\right.$ and $\delta^{2} \mathrm{H}_{\text {Sliq }}[\%$ VSMOW] $)$ profiles from day of experiment (DoE) 0-100 (top panel), from DoE 101-287 (middle panel), and from DoE 288-299 (bottom panel).

abovementioned equilibrium values after about 3.5 days. $\delta_{\text {Svap }}$ at $-0.20 \mathrm{~m}$ evolved in a similar way, whereas at $-0.10 \mathrm{~m}$ the equilibrium values were reached after $6 \mathrm{~h}$. Finally, $\delta_{\text {Svap }}$ at -0.40 and $-0.60 \mathrm{~m}$ and for both isotopologues were not affected by the water addition, which was consistent with the observed $\theta$ changes.

\subsection{Evolution of soil temperature, water content and $\delta_{\text {Sliq }}$ profiles}

In Fig. 5, $T_{\mathrm{S}}, \theta$ and $\delta_{\text {Sliq }}$ profiles for both isotopologues are plotted in three different panels, from DoE 0 to 100 (Fig. 5ad, top panels), from DoE 101 to 287 (Fig. 5e-h, center panels) and from DoE 288 to 299 (Fig. 5i-l, bottom panels). The represented profiles were obtained from a linear interpolation of the times series of each variable. Thus, since the measuring sequence started each day at 08:00 LT and ended at 18:00 LT, the depicted profiles are centered on 13:00 LT.

Even if the soil temperature fluctuated during the course of the experiment, quasi-isothermal conditions were fulfilled at a given date, as the column was not isolated from its surroundings. On average, $T_{\mathrm{S}}$ only varied by $0.2^{\circ} \mathrm{C}$ around the profile mean temperature at a given date. The $\delta_{\text {Sliq }}$ profiles showed a typical exponential shape from DoE 0 to approx. 100. Around DoE 100, when $\theta$ at $-0.01 \mathrm{~m}$ reached a value of $0.090 \mathrm{~m}^{3} \mathrm{~m}^{-3}$ (i.e., significantly greater than the sand residual water content $\theta=0.035 \mathrm{~m}^{3} \mathrm{~m}^{-3}$, determined by Merz et al., 2014), the maximal $\delta_{\text {Sliq }}$ values were no longer observed at the surface and atmosphere water vapor started invading the first centimeter of soil. Note that this happened slightly faster for ${ }^{1} \mathrm{H}^{2} \mathrm{H}^{16} \mathrm{O}$ than for ${ }^{1} \mathrm{H}_{2}^{18} \mathrm{O}$. On DoE 290 , when the column was irrigated, the isotope profiles were partly reset to their initial state, i.e., constant over depth and close to -53.5 and $-8.2 \%$ o for ${ }^{1} \mathrm{H}^{2} \mathrm{H}^{16} \mathrm{O}$ and ${ }^{1} \mathrm{H}_{2}^{18} \mathrm{O}$, respectively, with the exception of still higher values at $-0.07 \mathrm{~m}$.

\section{6 $\delta^{2} \mathbf{H}-\delta^{18} \mathrm{O}$ relationships in soil water and atmosphere water vapor}

Each plot of Fig. 6 represents data of 50 consecutive days of experiment. Laboratory atmosphere water vapor $\delta^{2} \mathrm{H}$ and $\delta^{18} \mathrm{O}$ (gray symbols) were linearly correlated (linear regression relationships in gray dotted lines) during the entire experiment $\left(R^{2}\right.$ ranging between 0.74 and $0.90, F$-statistic 

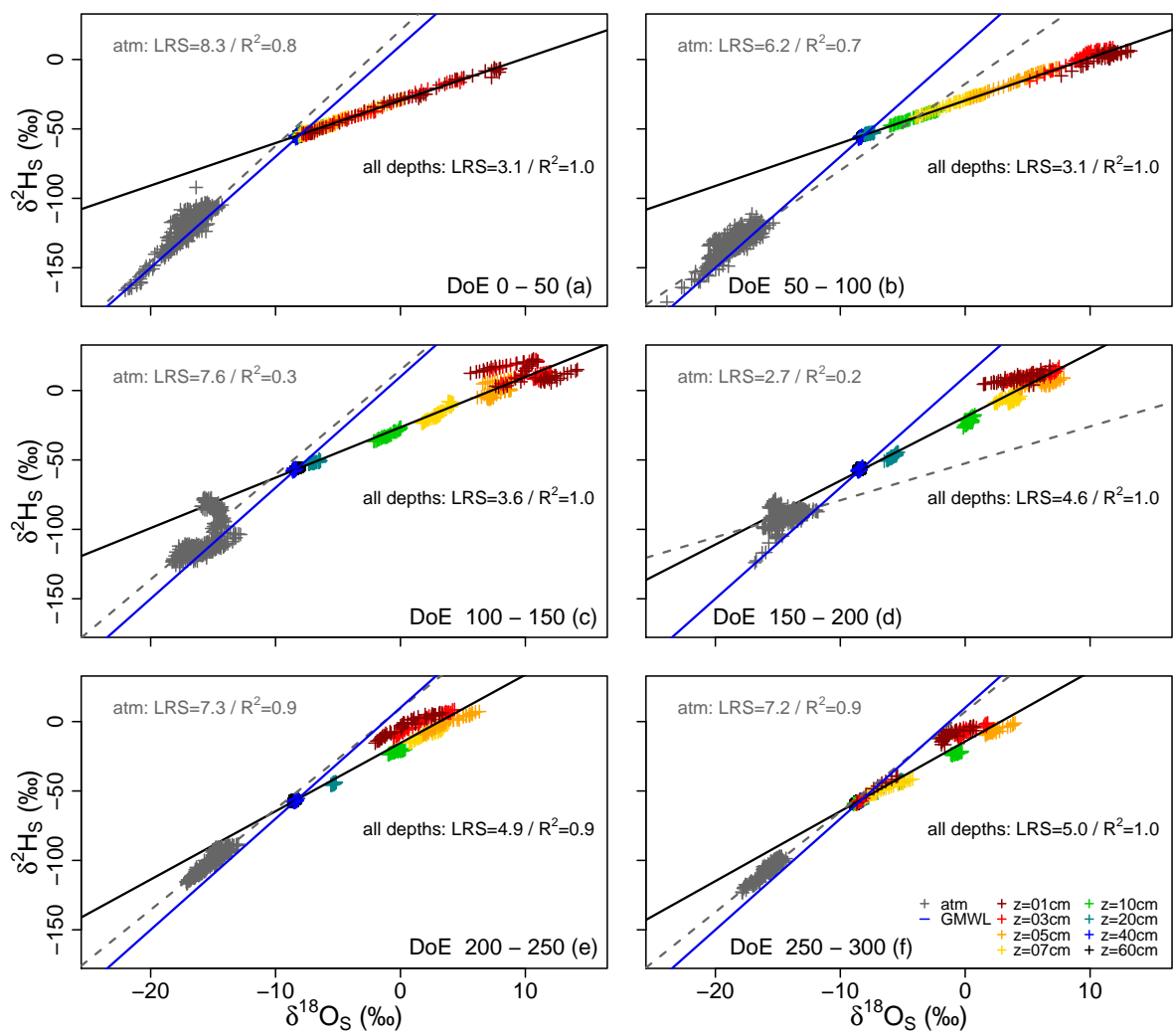

Figure 6. Linear regressions (gray dotted line) between laboratory atmosphere water vapor $\delta^{18} \mathrm{O}$ and $\delta^{2} \mathrm{H}$ [\%o VSMOW] and between soil water $\delta^{18} \mathrm{O}$ and $\delta^{2} \mathrm{H}$ (solid black line). Each plot represents data from 50 consecutive days of experiment (DoE). Global meteoric water line (GMWL; defined by $\delta^{2} \mathrm{H}=8 \times \delta^{18} \mathrm{O}+10$, in blue dotted line) is shown on each sub-plot for comparison. Coefficient of determination $\left(R^{2}\right)$ as well as the slope of the linear regressions (LRS) are reported.

$p$ value $<0.01$ ), with the exception of the period DoE $125-$ $155\left(R^{2}=0.31, p<0.001\right)$, when atmospheric water vapor $\delta^{2} \mathrm{H}$ was remarkably high in the laboratory (Fig. 6c and d).

The linear regression slopes (LRS) between $\delta^{2} \mathrm{H}_{\mathrm{a}}$ and $\delta^{18} \mathrm{O}_{\mathrm{a}}$ ranged from $6.20(\mathrm{DoE} 50-100, p<0.01)$ to 8.29 (DoE 0-50, gray dotted line, $p<0.001$ ). These values were significantly lower than $S_{\text {eq }}$, the calculated ratio between the liquid-vapor equilibrium fractionations of ${ }^{1} \mathrm{H}^{2} \mathrm{H}^{16} \mathrm{O}$ and ${ }^{1} \mathrm{H}_{2}^{18} \mathrm{O}$ (Majoube, 1971) that characterizes meteoric water bodies, which should have ranged from 8.41 to 8.92 at the measured monthly mean atmosphere temperatures (Forschungszentrum Jülich weather station, $6^{\circ} 24^{\prime} 34^{\prime \prime} \mathrm{E}$, $50^{\circ} 54^{\prime} 36^{\prime \prime} \mathrm{N}$; $91 \mathrm{~m}$ a.s.l.). Therefore, it can be deduced that the laboratory air moisture was partly resulting from column evaporation, typically leading to a $\delta^{2} \mathrm{H}-\delta^{18} \mathrm{O}$ regression slope of lower than eight. This also highlights the particular experimental conditions in the laboratory, where other sources of water vapor (e.g., by opening the laboratory door) might have influenced the isotope compositions of the air.

Considering all soil depths, the $\delta^{2} \mathrm{H}_{\text {Sliq }}-\delta^{18} \mathrm{O}_{\text {Sliq }}$ LRS increased from 2.96 to 4.86 over the course of the experiment (with $R^{2}>0.89, p<0.001$ ). These values were much lower than that of the slope of the global meteoric water line
(GMWL; i.e., slope $=8$ ) also represented in Fig. 6. However, Fig. 6 highlights the fact that in the upper three layers $(-0.01,-0.03$ and $-0.05 \mathrm{~m}) \delta^{2} \mathrm{H}_{\text {Sliq }}-\delta^{18} \mathrm{O}_{\text {Sliq }}$ LRS followed a significantly different evolution as the soil dried out. Figure 7 shows average $\delta^{2} \mathrm{H}-\delta^{18} \mathrm{O}$ LRS calculated for time intervals of 10 consecutive days for the atmosphere (gray line), the three upper layers (colored solid lines), and the remaining deeper layers $(-0.07,-0.10,-0.20,-0.40$ and $-0.60 \mathrm{~m}$, black dotted line). While both $\delta^{2} \mathrm{H}-\delta^{18} \mathrm{O}$ LRS in the atmosphere and in the first three depths fluctuated during the experiment, the combined LRS of the remaining deeper layers varied only little between 3.07 and 4.49 (average $=3.78 \pm 0.54$ ). From DoE $150, \delta^{2} \mathrm{H}-\delta^{18} \mathrm{O}$ LRS of the atmosphere and at $-0.01,-0.03$ and $-0.05 \mathrm{~m}$ in the soil were linearly correlated $\left(R^{2}=0.73,0.48\right.$ and 0.42 , with $p<0.001, p<0.01$ and $p<0.05$, respectively), whereas they were not correlated before DoE 125, demonstrating again the increasing influence of the atmosphere (atmospheric invasion) on the soil surface layer as the $\mathrm{EF}$ receded in the soil. Note the negative $\delta^{2} \mathrm{H}_{\mathrm{a}}-\delta^{18} \mathrm{O}_{\mathrm{a}} \mathrm{LRS}\left(R^{2}=0.26\right.$, $p<0.001$ ) observed between DoE 125 and 150, due to remarkably high atmosphere vapor $\delta^{2} \mathrm{H}$ measured in the laboratory. 


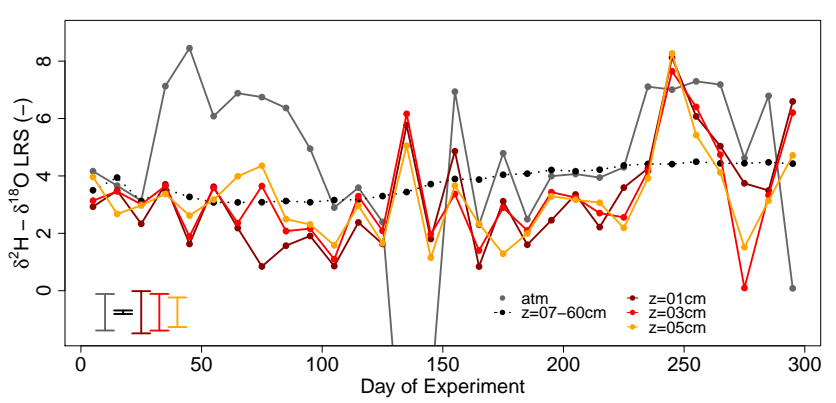

Figure 7. Time course of the slopes of the $\delta^{18} \mathrm{O}-\delta^{2} \mathrm{H}$ linear regressions (LRS) for time intervals of 10 consecutive days of atmosphere data (gray solid line), soil data from the upper three layers (1, 3, and $5 \mathrm{~cm}$, colored solid lines), and combined soil data from the remaining bottom layers (from 7 to $60 \mathrm{~cm}$, black dotted line). Mean standard errors are represented by the error bars in the bottom left corner.

\section{Discussion}

\subsection{Long-term reliability of the method}

The method proved to be reliable in the long term as the tubing sections positioned at -0.60 and $-0.40 \mathrm{~m}$ (i.e., where the sand was saturated or close to saturation during the entire experiment) remained watertight even after 299 days. As demonstrated by Rothfuss et al. (2013), (i) the length of the gas-permeable tubing, (ii) the low synthetic dry air flow rate, and (iii) the daily measurement frequency allowed for removing soil water vapor which remained under thermodynamic equilibrium with the soil moisture. Moreover, this was also true for the upper soil layers even at low soil water content; steady values for water vapor mixing ratio and isotope compositions were always reached during sampling throughout the experiment. Finally, our method enabled inferring the isotope composition of tightly bound water at the surface. This would be observable by the traditional vacuum distillation method with certainly a lower vertical resolution due to low moisture content. As also pointed out by Rothfuss et al. (2013), it can be assumed that the sand properties did not cause any fractionation of pore water ${ }^{2} \mathrm{H}$ and ${ }^{18} \mathrm{O}$. In contrast, this could not be the case in certain soils with high cation exchange capacity (CEC) as originally described by Sofer and Gat (1972) and recently investigated by Oerter et al. (2014).

\subsection{Locating the evaporation front depth from soil water $\delta^{2} \mathrm{H}$ and $\delta^{18} \mathrm{O}$ profiles}

From Fig. 4b no distinct characteristic evaporation stages, i.e., stages I and II referring to atmosphere-controlled and soil-controlled evaporation phases, respectively, could be identified. The opposite was observed by Merz et al. (2014), who conducted an evaporation study using the same sand. This indicates greater wind velocity in the air layer above the soil column due to the laboratory ventilation. For higher wind velocities, the boundary layer above the drying medium is thinner and the transfer resistance for vapor transfer lower than for lower wind velocities. But for thinner boundary layers, the evaporation rates depend more strongly on the spatial configuration of the vapor field above the partially wet evaporating surface. This makes the evaporation rate decrease and the transfer resistance in the boundary layer increase more in relative terms with decreasing water content of the evaporation surface for higher than for lower wind velocities (Shahraeeni et al., 2012).

Locating the EF in the soil is of importance for evapotranspiration partitioning purposes; from the soil water isotope composition at the EF, it is possible to calculate the evaporation flux isotope composition using the Craig and Gordon formula (Craig and Gordon, 1965). For a uniform isotope diffusion coefficient distribution in the liquid phase, an exponential decrease of the isotope composition gradient with depth is expected. However, when evaporation and thus accumulation of isotopologues occur in a soil layer between two given observation points, then the isotope gradient between these two points is smaller than the gradient deeper in the profile. Therefore, we can consider the time when the isotope composition gradient is no longer the largest between these two upper observation depths as the time when the EF moves into the soil layer below.

Figure $8 \mathrm{a}$ and $\mathrm{b}$ display the evolutions of the isotope compositions gradients $\mathrm{d}\left(\delta^{18} \mathrm{O}_{\mathrm{S}}\right) / \mathrm{d} z$ and $\mathrm{d}\left(\delta^{2} \mathrm{H}_{\mathrm{S}}\right) / \mathrm{d} z$ calculated between two consecutive observation points in the soil (between -0.01 and $-0.03 \mathrm{~m}$ in brown solid line, between -0.03 and $-0.05 \mathrm{~m}$ in red solid line, etc.). Figure $8 \mathrm{c}$ translates these isotope gradients in terms of $\mathrm{EF}$ depths $\left(z^{18} \mathrm{O}_{\mathrm{EF}}\right.$ and $\left.z^{2} \mathrm{H}_{\mathrm{EF}}\right)$. Each day, the maximum $\mathrm{d}\left(\delta^{18} \mathrm{O}_{\mathrm{S}}\right) / \mathrm{d} z$ and $\mathrm{d}\left(\delta^{2} \mathrm{H}_{\mathrm{S}}\right) / \mathrm{d} z$ define the layer where evaporation occurs, e.g., when $\mathrm{d}\left(\delta^{18} \mathrm{O}_{\mathrm{S}}\right) / \mathrm{d} z$ is maximal between -0.01 and $-0.03 \mathrm{~m}$ on a given DoE, $z^{18} \mathrm{O}_{\mathrm{EF}}$ is estimated to be greater than $-0.01 \mathrm{~m}$ and is assigned the value of $0 \mathrm{~m}$. When $\mathrm{d}\left(\delta^{18} \mathrm{O}_{\mathrm{S}}\right) / \mathrm{d} z$ is maximal between -0.03 and $-0.05 \mathrm{~m}$ on a given DoE, $z^{18} \mathrm{O}_{\mathrm{EF}}$ is estimated to range between -0.01 and $-0.03 \mathrm{~m}$ and is assigned the value $-0.02 \mathrm{~m}$. From both $\mathrm{d}\left(\delta^{18} \mathrm{O}_{\mathrm{S}}\right) / \mathrm{d} z$ and $\mathrm{d}\left(\delta^{2} \mathrm{H}_{\mathrm{S}}\right) / \mathrm{d} z$, a similar evolution of the depth of the EF was derived despite the fact that $\delta^{2} \mathrm{H}_{\text {Sliq }}$ and $\delta^{18} \mathrm{O}_{\text {Sliq }}$ time courses were different and showed maxima at different times. It was inferred that after 290 days under the prevailing laboratory air temperature, moisture and aerodynamic conditions, and given the specific hydraulic properties of the sand, the EF had moved down to an approximate depth of $-0.06 \mathrm{~m}$.

\subsection{Kinetic isotope effects during soil evaporation}

For each period of 10 consecutive days, the minimum measured $\delta^{2} \mathrm{H}_{\text {Sliq }}$ and $\delta^{18} \mathrm{O}_{\text {Sliq }}$ provided $\delta^{2} \mathrm{H}_{\text {Sliq_ini }}$ and $\delta^{18} \mathrm{O}_{\text {Sliq_ini }}$ in Eq. (3). $\delta^{2} \mathrm{H}_{\mathrm{a}}$ and $\delta^{18} \mathrm{O}_{\mathrm{a}}$ were obtained from the mean values of their respective times series. Mean soil surface water content $\left(\theta_{\text {surf }}\right)$ measured in the layer above the 

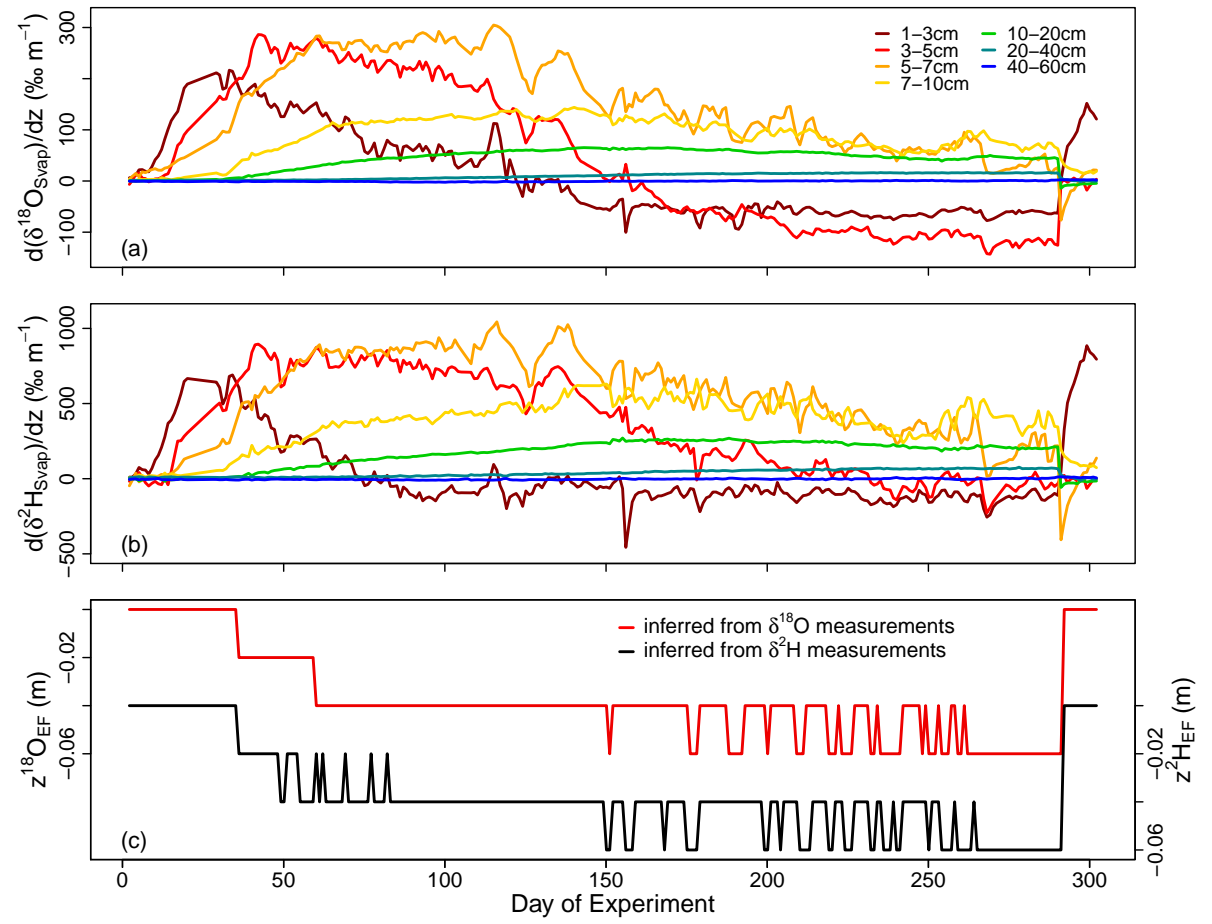

Figure 8. (a) and (b) ${ }^{1} \mathrm{H}_{2}^{18} \mathrm{O}$ and ${ }^{1} \mathrm{H}_{2} \mathrm{H}^{16} \mathrm{O}$ composition gradients calculated between consecutive observation points in the soil. (c) Evolution of the evaporation front depths $z^{18} \mathrm{O}_{\mathrm{EF}}[\mathrm{m}]$ (red solid line) and $z^{2} \mathrm{H}_{\mathrm{EF}}[\mathrm{m}]$ (black solid line) inferred from the ${ }^{1} \mathrm{H}_{2}^{18} \mathrm{O}$ and ${ }^{1} \mathrm{H}^{2} \mathrm{H}^{16} \mathrm{O}$ composition gradients.

EF (as identified in Sect. 4.2) provided the $n$ parameter in Eq. (5) and ultimately $\varepsilon_{\mathrm{K}}^{2 \mathrm{H}}$ and $\varepsilon_{\mathrm{K}}^{18_{\mathrm{O}}}\left(\right.$ Eq. 5). $\varepsilon_{\mathrm{eq}}^{2 \mathrm{H}}$ and $\varepsilon_{\mathrm{eq}}^{18_{\mathrm{O}}}$ were calculated from Majoube (1971) at the mean soil temperature measured at $z_{\mathrm{EF}}$. Relative humidity was normalized to the soil temperature measured at the EF. Finally, standard error for $S_{\mathrm{Ev}}$ was obtained using an extension of the formula proposed by Phillips and Gregg (2001) and detailed by Rothfuss et al. (2010). For this, standard errors associated with the determination of the variables in Eq. (3) were taken equal to their measured standard deviations for each time period. Standard errors for the parameters $\theta_{\text {res }}$ and $\theta_{\text {sat }}$ were set to $0.01 \mathrm{~m}^{3} \mathrm{~m}^{-3}$ (i.e., comparable to the precision of the soil water content probes) and for the diffusivity ratios $D / D^{2 \mathrm{H}}$ and $D / D^{18}$ o to zero (i.e., no uncertainty about their value was taken into account, although debatable; e.g., Cappa et al., 2003).

Figure 9a shows the comparison between time courses of $S_{\mathrm{Ev}}$ and $\delta^{2} \mathrm{H}_{\text {Sliq }}-\delta^{18} \mathrm{O}_{\text {Sliq }}$ LRS computed with data below the EF. Both ranged between 2.9 and 4.8, i.e., within the range of reported values (e.g., Barnes and Allison, 1988; Brunel et al., 1995; DePaolo et al., 2004). Note that values of both observed and simulated slopes increased over time, even though the air layer above the EF gradually increased as the soil dried out. The opposite was observed by, e.g., Barnes and Allison (1983), who simulated isotopic profiles at steady state with constant relative humidity. In the present study, however, the relative humidity of the atmosphere gradually increased, which in turn decreased the kinetic effects associated with ${ }^{1} \mathrm{H}^{2} \mathrm{H}^{16} \mathrm{O}$ and ${ }^{1} \mathrm{H}_{2}^{18} \mathrm{O}$ vapor transport and thus increased slopes over time. The general observed trend was very well reproduced by the model between DoE 30 and 150 $\left(\mathrm{NSE}=0.92\right.$; Nash and Sutcliffe, 1970), whereas $S_{\mathrm{Ev}}$ departed from data from DoE 150 onwards $(\mathrm{NSE}<0)$. Overall, the Craig and Gordon (1965) model could explain about $62 \%$ of the data variability with a root mean square error (RMSE) of 0.58 (and $76 \%$ when data from the period DoE $0-10$ are left out, $p$ value $<0.001$, RMSE $=0.52$ ). At the beginning of the experiment (DoE 0-20), simulated values were greater than computed $\delta^{2} \mathrm{H}-\delta^{18} \mathrm{O}$ LRS, even when taking into account the high $S_{\mathrm{Ev}}$ standard errors due to fast changing $\theta_{\text {surf }}$ (Phillips and Gregg, 2001). Although $S_{\mathrm{Ev}}$ was equal to 3.8 for the period DoE $0-10, \delta^{2} \mathrm{H}-\delta^{18} \mathrm{O}$ LRS had already reached (down) a value of 2.9 , meaning that the EF should have been no longer at the surface (i.e., between the surface and $0.01 \mathrm{~m}$ depth) leading to greater $n$, therefore lower slope value.

After DoE 150 and until DoE 290, when evaporation flux was lower than $0.40 \mathrm{~mm}_{\text {day }^{-1}}{ }^{-1}$, the difference between model and data progressively increased. For a better modelto-data fit, the ${ }^{1} \mathrm{H}^{2} \mathrm{H}^{16} \mathrm{O}$ and ${ }^{1} \mathrm{H}_{2}^{18} \mathrm{O}$ kinetic effects should decrease, through either (i) decrease of $n$, which from a theoretical point of view contradicts, e.g., the formulation of Mathieu and Bariac (1996), or (ii) decrease of term (1 - RH), 

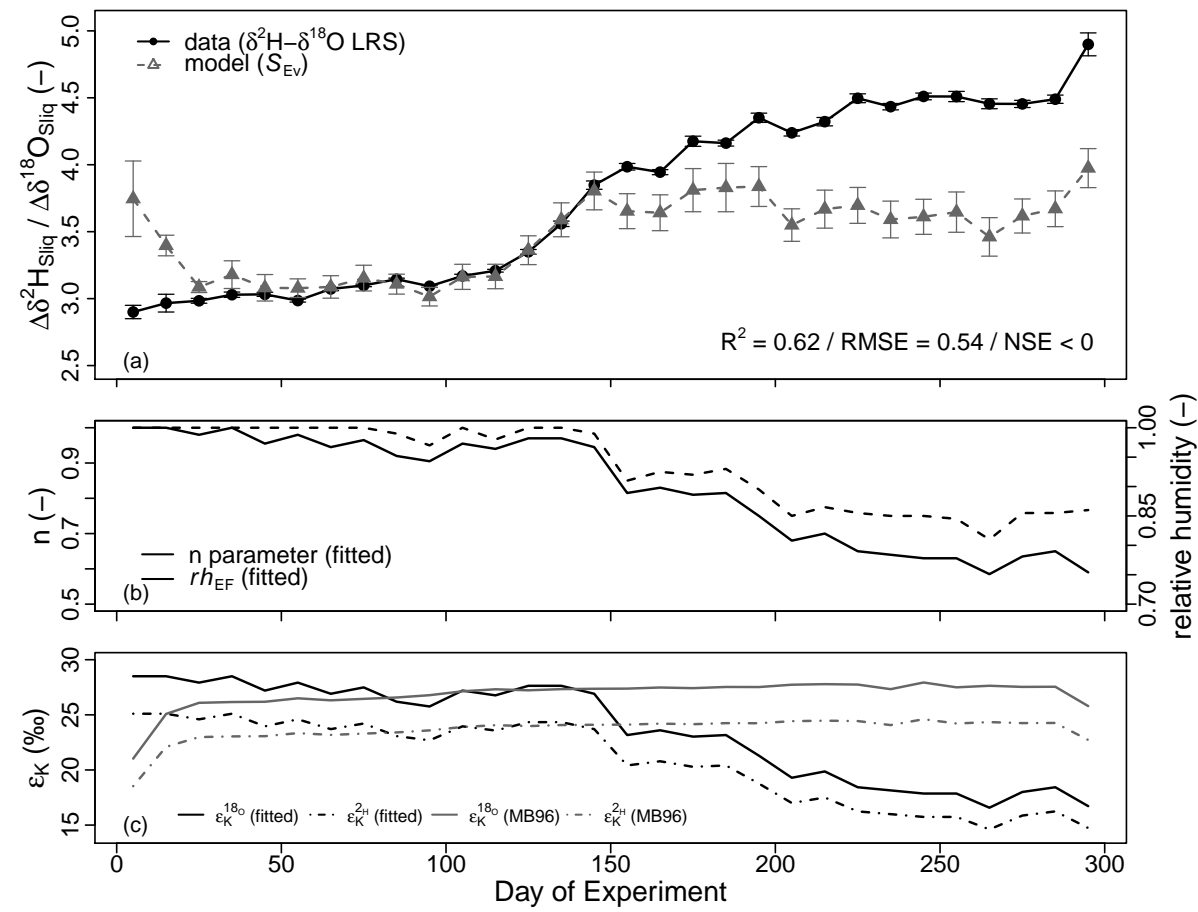

Figure 9. (a) Comparison between soil liquid water $\delta^{18} \mathrm{O}-\delta^{2} \mathrm{H}$ linear regressions slopes (LRS, solid black line) calculated for time intervals of 10 consecutive days and simulated time series of evaporation line slope ( $S_{\mathrm{Ev}}$, dotted gray line) obtained from Eqs. (3)-(6) (Gat, 1971; Merlivat, 1978; Mathieu and Bariac, 1996). Black error bars give the standard errors of the estimated $\delta^{18} \mathrm{O}-\delta^{2} \mathrm{H}$ LRS. Gray error bars are the standard errors associated with calculation of $S_{\mathrm{Ev}}$ following Phillips and Gregg (2001). Coefficient of determination $\left(R^{2}\right)$, root mean square error (RMSE) and Nash and Sutcliffe efficiency (NSE) between model and data are reported. (b) Time series of $n$ parameter (Eq. 6) and soil relative humidity at the evaporation front $\left(\mathrm{RH}_{\mathrm{EF}}\right)$ that provided the best model-to-data fit. (c) $\varepsilon_{\mathrm{K}}^{2 \mathrm{H}}$ and $\varepsilon_{\mathrm{K}}^{18_{\mathrm{O}}}$ time series obtained from fitted n values ("fitted") and calculated following Mathieu and Bariac (1996) ("MB96").

or else (iii) a combination of (i) and (ii). In another laboratory study where $\delta^{18} \mathrm{O}$ of water in bare soil columns was measured destructively, and $\delta^{18} \mathrm{O}$ of evaporation was estimated from cryogenic trapping of water vapor at the outlet of the columns' headspaces, Braud et al. (2009a, b) could capture $\varepsilon_{\mathrm{K}}^{18 \mathrm{O}}$ dynamics by inverse modeling. In their case, $\varepsilon_{\mathrm{K}}^{18 \mathrm{O}}$ generally reached values close to $\varepsilon_{\mathrm{K}}^{18 \mathrm{O}}=18.9 \%$ o corresponding to laminar conditions above the liquid-vapor interface $(n=2 / 3)$. However, they found values lower than reported in the literature (i.e., $\varepsilon_{\mathrm{K}}^{18_{0}}<14.1 \%$ ) at the end of their experiments, when the dry soil surface layer had increased in thickness and soil surface relative humidity was significantly lower than $100 \%$. These results were partly explained by the particular experimental conditions leading to uncertainties in characterizing the isotope compositions of evaporation when the dry soil surface layer was developed the most. Nevertheless, the same observation was made in the present study despite a different soil texture (silt loam versus quartz sand) and noticeably different atmospheric conditions ("free" laboratory atmosphere versus sealed headspace circulated with dry air). Figure $9 \mathrm{c}$ displays the evolution of $\varepsilon_{\mathrm{K}}^{2 \mathrm{H}}$ (resp. $\varepsilon_{\mathrm{K}}^{18 \mathrm{O}}$ ) that provided the best fit with the data (NSE $=0.99)$ by fitting the $n$ parameter (shown in Fig. 9b) instead of calculating it with Eq. (5). In this scenario, $n$ decreased from one to 0.59 , with a mean value of $0.96 \pm 0.03$ during the period DoE 0 150.

Instead of changing the value of $n$ over time (and therefore those of $\varepsilon_{\mathrm{K}}^{2 \mathrm{H}}$ and $\varepsilon_{\mathrm{K}}^{18 \mathrm{O}}$ ), another possibility is to consider that after some time the relative humidity at the $\mathrm{EF}\left(\mathrm{RH}_{\mathrm{EF}}\right)$ was different from $100 \%$, although the EF was still at thermodynamic equilibrium. In that case kinetic effects would have depended on the difference $\left(\mathrm{RH}_{\mathrm{EF}}-\mathrm{RH}\right)$ instead of (1$\mathrm{RH})$. Figure $9 \mathrm{~b}$ shows the $\mathrm{RH}_{\mathrm{EF}}$ time course that provided the best model-to-data fit $(\mathrm{NSE}=0.92)$, when $\varepsilon_{\mathrm{K}}^{2 \mathrm{H}}$ and $\varepsilon_{\mathrm{K}}^{18 \mathrm{O}}$ were calculated (Eqs. 5 and 6). In this second scenario, $\mathrm{RH}_{\mathrm{EF}}$ decreased from 100 to $81 \%$ with a mean value of $99.5 \pm 0.03 \%$ for the period DoE 0-150, i.e., in a similar fashion than fitted $\mathrm{n}$ values obtained in the first scenario. These values were significantly lower than those calculated with Kelvin's equation linking $\mathrm{RH}_{\mathrm{EF}}$ with soil water tension at the $\mathrm{EF}$ in the case of liquid-vapor equilibrium, which for the given soil retention properties (Merz et al., 2014) would range between 100 and $99.6 \%$. In a third scenario one could consider a combined decrease of $n$ and $\mathrm{RH}_{\mathrm{EF}}$ to a smaller extent, for which there are no unique solutions at each time step. In a fourth scenario, the ratio of turbulent diffusion resistance to molecular 
diffusion resistance is no more negligible, leading to $n^{\prime}$ values ranging between 0 and $n$ (Merlivat and Jouzel, 1979). This last scenario was, however, not verifiable. In any case, only decreasing kinetic effects could provide a better modelto-data fit. Note that the formulation of kinetic enrichments proposed by Merlivat and Coantic (1975) and based on the evaporation model of Brutsaert (1982) was not tested due to lack of appropriate data (i.e., unknown wind distribution profile over the soil column). The formulations of Melayah et al. (1996) $(n=0)$ and Barnes and Allison (1983) $(n=1)$ were also not tested as they give kinetic enrichments constant over time and cannot explain a change of $S_{\mathrm{Ev}}$ value through change of $n$. Finally, $S_{\mathrm{Ev}}$ calculations using diffusivity ratios determined by Cappa et al. (2003) lead to lower values of $S_{\mathrm{Ev}}$ and a less good model-to-data fit.

In the present study, information on $\delta^{2} \mathrm{H}$ and $\delta^{18} \mathrm{O}$ of the evaporation flux was missing to address uncertainties in the determination of $\varepsilon_{\mathrm{K}}^{2 \mathrm{H}}$ and $\varepsilon_{\mathrm{K}}^{18 \mathrm{O}}$. The experimental setup would also have benefited from the addition of appropriate sensors (e.g., micro-psychrometers) to measure the soil surface relative humidity and especially $\mathrm{RH}_{\mathrm{EF}}$, although the dimensions of the column would certainly be a limiting factor. A more indepth investigation of the behavior of $S_{\mathrm{Ev}}$ (and isotope composition gradients with depth for that matter) with time could be carried out with detailed numerical simulations using an isotope-enabled SVAT model such as SiSPAT-Isotope.

\section{Conclusions}

Since the initial work of Zimmermann et al. (1967), water stable isotopologues have proven both theoretically and experimentally to be valuable tools for the study of water flow in the soil and at the soil-atmosphere interface. In this work we present the first application of the method of Rothfuss et al. (2013). This study constitutes also the very first long-term application of the series of newly developed isotopic monitoring systems based on gas-permeable tubing and isotopespecific infrared laser absorption spectroscopy (Herbstritt et al., 2012; Volkmann and Weiler, 2014). Our method proved to be reliable over long time periods and followed quantitatively the progressive isotope enrichment caused by evaporation in an initially saturated soil column. Moreover, it could capture sudden variations following a simulated intense rain event.

Simple calculations of isotope gradients made it possible to evaluate the position of the EF and observe how it progressively receded with time in the soil. Confrontation of the model of Craig and Gordon (1965) with data of the present study also highlighted uncertainties associated with the determination of kinetic isotope fractionations and soil relative humidity at the EF when the soil surface dry layer was developed the most and evaporation flux was low.

Our method will allow experimentalists to measure and locate the evaporation front in a dynamic and non-destructive manner and to calculate the isotope compositions of the evaporation flux using the model of Craig and Gordon (1965) with much higher time resolution. Provided that the isotope compositions of evapotranspiration and transpiration fluxes are measured or modeled, this method will be especially useful to test hypotheses and improve our understanding of root water uptake processes and the partitioning of evapotranspiration fluxes.

Acknowledgements. This study was conducted in the framework of and with means from the Bioeconomy Portfolio Theme of the Helmholtz Association of German Research Centers. The authors would like to thank one reviewer for his valuable input, Ayhan Egmen and Dieter Mans from the IBG Workshop at Forschungszentrum Jülich for designing and building the acrylic glass column and Holger Wissel for his insight and technical support. Special thanks go to the Institute of Meteorology and Climate Research (IMK-IFU), Karlsruhe Institute of Technology, for providing the water isotopic analyzer for this study.

The article processing charges for this open-access publication were covered by a Research Centre of the Helmholtz Association.

Edited by: C. Stumpp

\section{References}

Barnes, C. J. and Allison, G. B.: The Distribution of Deuterium and ${ }^{18} \mathrm{O}$ in Dry Soils, 1. Theory, J. Hydrol., 60, 141-156, doi:10.1016/0022-1694(83)90018-5, 1983.

Barnes, C. J. and Allison, G. B.: The Distribution of Deuterium and ${ }^{18} \mathrm{O}$ in Dry Soils, 3. Theory for Non-Isothermal Water-Movement, J. Hydrol., 74, 119-135, doi:10.1016/00221694(84)90144-6, 1984.

Barnes, C. J. and Allison, G. B.: Tracing of water movement in the unsaturated zone using stable isotopes of hydrogen and oxygen, J. Hydrol., 100, 143-176, doi:10.1016/0022-1694(88)90184-9, 1988.

Barnes, C. J. and Walker, G. R.: The Distribution of Deuterium and ${ }^{18} \mathrm{O}$ during Unsteady Evaporation from a Dry Soil, J. Hydrol., 112, 55-67, doi:10.1016/0022-1694(89)90180-7, 1989.

Blasch, K. W. and Bryson, J. R.: Distinguishing sources of ground water recharge by using $\delta^{2} \mathrm{H}$ and $\delta^{18} \mathrm{O}$, Ground Water, 45, 294 308, doi:10.1111/j.1745-6584.2006.00289.x, 2007.

Braud, I., Bariac, T., Gaudet, J. P., and Vauclin, M.: SiSPATIsotope, a coupled heat, water and stable isotope (HDO and $\mathrm{H}_{2}^{18} \mathrm{O}$ ) transport model for bare soil, Part I. Model description and first verifications, J. Hydrol., 309, 277-300, doi:10.1016/j.jhydrol.2004.12.013, 2005.

Braud, I., Biron, P., Bariac, T., Richard, P., Canale, L., Gaudet, J. P., and Vauclin, M.: Isotopic composition of bare soil evaporated water vapor, Part I: RUBIC IV experimental setup and results, J. Hydrol., 369, 1-16, doi:10.1016/j.jhydrol.2009.01.034, 2009a.

Braud, I., Bariac, T., Biron, P., and Vauclin, M.: Isotopic composition of bare soil evaporated water vapor, Part II: Model- 
ing of RUBIC IV experimental results, J. Hydrol., 369, 17-29, doi:10.1016/j.jhydrol.2009.01.038, 2009b.

Brunel, J. P., Walker, G. R., and Kennettsmith, A. K.: Field Validation of Isotopic Procedures for Determining Sources of Water Used by Plants in a Semiarid Environment, J. Hydrol., 167, 351368, doi:10.1016/0022-1694(94)02575-V 1995.

Brutsaert, W.: A theory for local evaporation (or heat transfer) from rough and smooth surfaces at ground level, Water Resour. Res., 11, 543-550, doi:10.1029/WR011i004p00543, 1975.

Brutsaert, W.: Evaporation into the Atmosphere, in: Theory, History and Applications, Environmental Fluid Mechanics, 1, edited by: Davenport, A. J., Hicks, B. B., Hilst, G. R., Munn, R. E., and Smith, J. D., Springer Netherlands, 1982.

Cappa, C. D., Hendricks, M. B., DePaolo, D. J., and Cohen, R. C.: Isotopic fractionation of water during evaporation, J. Geophys. Res.-Atmos., 108, 4525, doi:10.1029/2003jd003597, 2003.

Craig, H.: Isotopic Variations in Meteoric Waters, Science, 133, 1702-1703, doi:10.1126/science.133.3465.1702, 1961.

Craig, H. and Gordon, L. I.: Deuterium and oxygen 18 variations in the ocean and marine atmosphere, Stable Isotopes in Oceanographic Studies and Paleotemperatures, Spoleto, Italy, 9-130, 1965.

DePaolo, D. J., Conrad, M. E., Maher, K., and Gee, G. W.: Evaporation effects on oxygen and hydrogen isotopes in deep vadose zone pore fluids at Hanford, Washington, Vadose Zone J., 3, 220 232, doi:10.2113/3.1.220, 2004.

Dongmann, G., Nurnberg, H. W., Forstel, H., and Wagener, K.: Enrichment of $\mathrm{H}_{2}^{18} \mathrm{O}$ in Leaves of Transpiring Plants, Radiat. Environ. Bioph., 1, 41-52, doi:10.1007/Bf01323099, 1974.

Dubbert, M., Cuntz, M., Piayda, A., Maguás, C., and Werner, C.: Partitioning evapotranspiration - Testing the Craig and Gordon model with field measurements of oxygen isotope ratios of evaporative fluxes, J. Hydrol., 496, 142-153, doi:10.1016/j.jhydrol.2013.05.033, 2013.

Gaj, M., Beyer, M., Koeniger, P., Wanke, H., Hamutoko, J., and Himmelsbach, T.: In-situ unsaturated zone stable water isotope $\left({ }^{2} \mathrm{H}\right.$ and $\left.{ }^{18} \mathrm{O}\right)$ measurements in semi-arid environments using tunable off-axis integrated cavity output spectroscopy, Hydrol. Earth Syst. Sci. Discuss., 12, 6115-6149, doi:10.5194/hessd-126115-2015, 2015.

Gat, J. R.: Comments on the Stable Isotope Method in Regional Groundwater Investigations, Water Resour. Res., 7, 980-993, doi:10.1029/WR007i004p00980, 1971.

Gat, J. R.: Atmospheric water balance - the isotopic perspective, Hydrol. Process., 14, 1357-1369, doi:10.1002/10991085(20000615)14:8<1357::AID-HYP986>3.0.CO;2-7, 2000.

Goldsmith, G. R., Munoz-Villers, L. E., Holwerda, F., McDonnell, J. J., Asbjornsen, H., and Dawson, T. E.: Stable isotopes reveal linkages among ecohydrological processes in a seasonally dry tropical montane cloud forest, Ecohydrology, 5, 779-790, doi:10.1002/eco.268, 2011.

Gonfiantini, R.: Standards for stable isotope measurements in natural compounds, Nature, 271, 534-536, doi:10.1038/271534a0, 1978.

Haverd, V. and Cuntz, M.: Soil-Litter-Iso: A one-dimensional model for coupled transport of heat, water and stable isotopes in soil with a litter layer and root extraction, J. Hydrol., 388, 438455, doi:10.1016/j.jhydrol.2010.05.029, 2010.
Herbstritt, B., Gralher, B., and Weiler, M.: Continuous in situ measurements of stable isotopes in liquid water, Water Resour. Res., 48, W03601, doi:10.1029/2011wr011369, 2012.

Hu, Z. M., Wen, X. F., Sun, X. M., Li, L. H., Yu, G. R., Lee, X. H., and Li, S. G.: Partitioning of evapotranspiration through oxygen isotopic measurements of water pools and fluxes in a temperate grassland, J. Geophys. Res.-Biogeo., 119, 358-371, doi:10.1002/2013jg002367, 2014.

Jasechko, S., Sharp, Z. D., Gibson, J. J., Birks, S. J., Yi, Y., and Fawcett, P. J.: Terrestrial water fluxes dominated by transpiration, Nature, 496, 347-351, doi:10.1038/Nature11983, 2013.

Litaor, M. I.: Review of Soil Solution Samplers, Water Resour. Res., 24, 727-733, doi:10.1029/Wr024i005p00727, 1988

Liu, Z. F., Bowen, G. J., and Welker, J. M.: Atmospheric circulation is reflected in precipitation isotope gradients over the conterminous United States, J. Geophys. Res.-Atmos., 115, D22120, doi:10.1029/2010jd014175, 2010.

Majoube, M.: Oxygen-18 and Deuterium Fractionation between Water and Steam, J. Chim. Phys. Phys.-Chim. Biol., 68, 14231436, 1971.

Mathieu, R. and Bariac, T.: A numerical model for the simulation of stable isotope profiles in drying soils, 101, 12685-12696, J. Geophys. Res.-Atmos., 101, 12685-12696, doi:10.1029/96jd00223, 1996.

Melayah, A., Bruckler, L., and Bariac, T.: Modeling the transport of water stable isotopes in unsaturated sails under natural conditions, 1. Theory, Water Resour. Res., 32, 2047-2054, doi:10.1029/96wr00674, 1996.

Merlivat, L.: Molecular Diffusivities of $\mathrm{H}_{2}^{16} \mathrm{O}, \mathrm{HD}^{16} \mathrm{O}$, and $\mathrm{H}_{2}^{18} \mathrm{O}$ in Gases, J. Chem. Phys., 69, 2864-2871, doi:10.1063/1.436884, 1978.

Merlivat, L. and Coantic, M.: Study of Mass-Transfer at Air-WaterInterface by an Isotopic Method, J. Geophys. Res.-Oceans, 80, 3455-3464, doi:10.1029/Jc080i024p03455, 1975.

Merlivat, L. and Jouzel, J.: Global Climatic Interpretation of the Deuterium-Oxygen-18 Relationship for Precipitation, J. Geophys. Res.-Oceans, 84, 5029-5033, doi:10.1029/JC084iC08p05029, 1979.

Merz, S., Pohlmeier, A., Vanderborght, J., van Dusschoten, D., and Vereecken, H.: Moisture profiles of the upper soil layer during evaporation monitored by NMR, Water Resour. Res., 50, 5184 5195, doi:10.1002/2013wr014809, 2014.

Murray, F. W.: On the Computation of Saturation Vapor Pressure, J. Appl. Meteorol., 6, 203-204, doi:10.1175/15200450(1967)006<0203:OTCOSV>2.0.CO;2, 1967.

Nash, J. E. and Sutcliffe, J. V.: River flow forecasting through conceptual models part I -A discussion of principles, J. Hydrol., 10, 282-290, doi:10.1016/0022-1694(70)90255-6, 1970.

Oerter, E., Finstad, K., Schaefer, J., Goldsmith, G. R., Dawson, T., and Amundson, R.: Oxygen isotope fractionation effects in soil water via interaction with cations $(\mathrm{Mg}, \mathrm{Ca}, \mathrm{K}, \mathrm{Na})$ adsorbed to phyllosilicate clay minerals, J. Hydrol., 515, 1-9, doi:10.1016/j.jhydrol.2014.04.029, 2014.

Peng, T. R., Lu, W. C., Chen, K. Y., Zhan, W. J., and Liu, T. K.: Groundwater-recharge connectivity between a hills-and-plains' area of western Taiwan using water isotopes and electrical conductivity, J. Hydrol., 517, 226-235, doi:10.1016/j.jhydrol.2014.05.010, 2014. 
Phillips, D. L. and Gregg, J. W.: Uncertainty in source partitioning using stable isotopes, Oecologia, 127, 171-179, doi:10.1007/s004420000578, 2001.

Rothfuss, Y., Biron, P., Braud, I., Canale, L., Durand, J. L., Gaudet, J. P., Richard, P., Vauclin, M., and Bariac, T.: Partitioning evapotranspiration fluxes into soil evaporation and plant transpiration using water stable isotopes under controlled conditions, Hydrol. Process., 24, 3177-3194, doi:10.1002/Hyp.7743, 2010.

Rothfuss, Y., Braud, I., Le Moine, N., Biron, P., Durand, J. L., Vauclin, M., and Bariac, T.: Factors controlling the isotopic partitioning between soil evaporation and plant transpiration: Assessment using a multi-objective calibration of SiSPATIsotope under controlled conditions, J. Hydrol., 442, 75-88, doi:10.1016/j.jhydrol.2012.03.041, 2012.

Rothfuss, Y., Vereecken, H., and Brüggemann, N.: Monitoring water stable isotopic composition in soils using gas-permeable tubing and infrared laser absorption spectroscopy, Water Resour. Res., 49, 1-9, doi:10.1002/wrcr.20311, 2013.

Schmidt, M., Maseyk, K., Lett, C., Biron, P., Richard, P., Bariac, T., and Seibt, U.: Concentration effects on laser-based $\delta^{18} \mathrm{O}$ and $\delta^{2} \mathrm{H}$ measurements and implications for the calibration of vapour measurements with liquid standards, Rapid Commun. Mass Spectrom., 24, 3553-3561, doi:10.1002/rcm.4813, 2010.

Shahraeeni, E., Lehmann, P., and Or, D.: Coupling of evaporative fluxes from drying porous surfaces with air boundary layer: Characteristics of evaporation from discrete pores, Water Resour. Res., 48, W09525, doi:10.1029/2012wr011857, 2012.

Singleton, M. J., Sonnenthal, E. L., Conrad, M. E., DePaolo, D. J., and Gee, G. W.: Multiphase reactive transport modeling of seasonal infiltration events and stable isotope fractionation in unsaturated zone pore water and vapor at the Hanford site, Vadose Zone J., 3, 775-785, doi:10.2113/3.3.775, 2004.
Sofer, Z. and Gat, J. R.: Activities and Concentrations of O18 in Concentrated Aqueous Salt Solutions - Analytical and Geophysical Implications, Earth Planet. Sc. Lett., 15, 232-238, doi:10.1016/0012-821x(72)90168-9, 1972.

Stingaciu, L. R., Pohlmeier, A., Blumler, P., Weihermuller, L. van Dusschoten, D., Stapf, S., and Vereecken, H.: Characterization of unsaturated porous media by high-field and lowfield NMR relaxometry, Water Resour. Res., 45, W08412, doi:10.1029/2008wr007459, 2009.

Sutanto, S. J., Wenninger, J., Coenders-Gerrits, A. M. J., and Uhlenbrook, S.: Partitioning of evaporation into transpiration, soil evaporation and interception: a comparison between isotope measurements and a HYDRUS-1D model, Hydrol. Earth Syst. Sci., 16, 2605-2616, doi:10.5194/hess-16-2605-2012, 2012.

Volkmann, T. H. M. and Weiler, M.: Continual in situ monitoring of pore water stable isotopes in the subsurface, Hydrol. Earth Syst. Sci., 18, 1819-1833, doi:10.5194/hess-18-1819-2014, 2014.

Wang, P., Song, X. F., Han, D. M., Zhang, Y. H., and Liu, X.: A study of root water uptake of crops indicated by hydrogen and oxygen stable isotopes: A case in Shanxi Province, China, Agr. Water Manage., 97, 475-482, doi:10.1016/j.agwat.2009.11.008, 2010.

Yepez, E. A., Huxman, T. E., Ignace, D. D., English, N. B., Weltzin, J. F., Castellanos, A. E., and Williams, D. G.: Dynamics of transpiration and evaporation following a moisture pulse in semiarid grassland: A chamber-based isotope method for partitioning flux components, Agr. Forest Meteorol., 132, 359-376, doi:10.1016/j.agrformet.2005.09.006, 2005.

Zimmermann, U., Ehhalt, D., and Münnich, K. O.: Soil water movement and evapotranspiration: changes in the isotopic composition of the water, Symposium of Isotopes in Hydrology, Vienna, 567-584, 1967. 